\title{
SURINAME: HISTÓRIA, LITERATURA E QUESTÕES DE TRADUÇÃO
}

\section{SURINAME: HISTORY, LITERATURE AND TRANSLATION ISSUES}

Julio Cesar Neves Monteiro

Universidade de Brasília

Brasília, Distrito Federal, Brasil

RESUMO: Ainda largamente desconhecida do público mundial, a literatura do nosso vizinho Suriname é uma agradável surpresa, uma vez vencidos os percalços para ter acesso a ela. Uma das razões a que se pode atribuir o fato de a literatura surinamesa permanecer um bemguardado segredo é sua produção ocorrer em uma língua de menor difusão, o neerlandês, mas a isso somam-se outras questões. Muito conhecida na ex-metrópole, circula pouco em traduções mundo afora. Este artigo tem como objetivo lançar luz sobre a possibilidade de que se possa estabelecer um diálogo entre os sistemas literários brasileiro e surinamês por meio da tradução para o português brasileiro de, entre outras obras, romances históricos surinameses, em especial os que têm a diáspora como tema. O Brasil e o Suriname compartilham uma história de migrações forçadas e relatos sobre essas migrações perpassam o sistema literário de ambos os países. Presume-se que o leitor brasileiro possa se interessar pela representação desses temas que lhe são tão familiares e que se disponha a ler literatura surinamesa traduzida para o português brasileiro.

PALAVRAS-CHAVE: Suriname; Literatura; História; Tradução

ABSTRACT: Still largely unknown to the world public, the literature of our neighbor Suriname is a pleasant surprise, once the mishaps have been overcome to gain access to it. One of the reasons that can be attributed to the fact that the Surinamese literature remains a well-kept secret is that its production takes place in the lesserknown Dutch language, but to this are added other questions. Very well known in the former metropolis, it circulates little in translations around the world. This article aims to shed light on the possibility of establishing a dialogue between the Brazilian and Surinamese literary systems through the translation into Brazilian Portuguese 
of, among other works, Surinamese historical novels, especially those that have the diaspora as theme. Brazil and Suriname share a history of forced migration and reports on these migrations permeates the literary system of both countries. It is assumed that the Brazilian reader may be interested in the representation of these themes that are so familiar to him and that he is willing to read Surinamese literature translated into Brazilian Portuguese. KEYWORDS: Suriname; Literature; History; Translation 
O Suriname é, talvez, o vizinho mais desconhecido do Brasil. Ao ouvir o nome "Suriname", muitos brasileiros logo imaginam algum lugar distante, talvez na África. são relativamente poucos os que conseguem localizar o país corretamente na porção norte do continente sul-americano.

$\mathrm{Na}$ verdade, quando se pensa na fronteira norte, o que em si já é algo raro, o que vem à mente de alguns brasileiros que não vivem na região norte do país, talvez resquício dos tempos de escola, é uma massa indistinta, as "Guianas", mas além da Guiana (ex Guiana Inglesa) e da Guiana Francesa, o que sobra na memória e no discurso do brasileiro médio é um grande vazio.

$\mathrm{Na}$ verdade, a história conturbada da região pouco fez para ajudar o brasileiro a entender melhor essa região. A Guiana Francesa e a Guiana, por algum motivo, talvez pelo fato de terem sido colonizadas por franceses e britânicos, permanecem de certa forma presentes no imaginário brasileiro. A outra Guiana, a Holandesa, jamais conseguiu um lugar nesse imaginário.

O fato é que, após muitas reorganizações e mudança de mãos, o que finalmente surgiu da então Guiana Holandesa foi o Suriname. O Suriname foi um lugar disputado por britânicos e holandeses até que, em 1667, o Tratado de Breda fez com que o território passasse de maneira definitiva para as mãos dos holandeses. Os holandeses estavam interessados em manter as plantações de açúcar e café na colônia e fizeram excelente negócio: em troca do Suriname, ofereceram aos ingleses um território algo inóspito na América do Norte, uma colônia chamada Nova Amsterdã. Se o brasileiro contemporâneo desconhece o Suriname, o Tratado de Breda e a Nova Amsterdã, certamente conhece Nova York, o nome atual do tal território do Norte. De 1667 até 1954, o Suriname permaneceu como colônia dos Países Baixos e de 1954 até a independência, em 1975, foi um país autônomo dentro do Reino dos Países Baixos.

Mas o que significou para o Suriname, em termos culturais e, evidentemente, literários, esse conturbado passado colonial? Para responder a essa pergunta, é preciso voltar à questão econômica que motivou a disputa pela soberania na região. O território que hoje chamamos de Suriname era ideal para o cultivo de cana de açúcar, commodity altamente valorizada na Europa do século XVII. Além disso, podia-se plantar também café, além de garantir aos holandeses uma base permanente no continente sul-americano após a saída do Nordeste brasileiro.

A fim de fazer girar a engrenagem de produção nos moldes do colonialismo, fez-se necessária a importação de mão-de-obra para a colônia, inicialmente sob a forma de africanos escravizados.

Os escravos negros foram levados ao país entre 1650 e 1808, vindos principalmente do Oeste da África. Os navios negreiros da Companhia da Índias Ocidentais, responsáveis tanto pela ocupação holandesa do Nordeste brasileiro como pela administração dos territórios que hoje chamamos Suriname, partiam do que hoje é Gana com destino à colônia. Quando não havia africanos escravizados em número suficiente, faziam paradas onde hoje é território angolano para que os navios cruzassem o oceano com lotação máxima. Brasil e Suriname, portanto, compartilham já no século XVII dois aspectos fundamentais: o jugo empresário- 
colonial holandês e parte da população com uma origem comum na África. Não serão esses os únicos aspectos a unir os dois países, como mostrarei mais adiante.

Nas plantações, os negros escravizados recebiam nomes cristãos e estavam oficialmente proibidos de praticar seus costumes, inclusive suas práticas religiosas e suas mitologias, inclusive suas narrativas épicas e cosmogônicas. Embora não lhes fosse mais permitido levar seu modo de vida tradicional, tampouco podiam incorporar elementos da cultura europeia: além da discussão sobre terem ou não alma - que contraria o batismo forçado de que eram vítimas -, eles estavam proibidos de usar sapatos e de se casar ou ter relações sexuais com brancos, entre outras limitações (JABINI, 2012, p. 96).

Um aspecto muito interessante da política colonial no Suriname, do ponto de vista da formação literária do país, é que os escravos negros eram proibidos de aprender a língua dos senhores, ou seja, estavam impedidos de falar holandês. Não podiam ler nem escrever nessa língua, embora alguns o fizessem, ao arrepio da lei. (ARNOLD 2001, WIENBERG et alii 2016). O fato é que, embora tenha tido muitas brechas do século XVII até meados do século XIX, essa proibição só foi oficialmente abolida em 1876, quando o governo colonial holandês estabeleceu a escolarização obrigatória para todos os segmentos da população surinamesa e impôs o idioma holandês como única língua de instrução, o que teve grande impacto na literatura nacional, pois o holandês passou a ser parte da herança do povo surinamês e essa língua se tornaria a principal na produção literária do país.

No Suriname atual são faladas cerca de 22 línguas. Se se considera que todas essas línguas possuem tradição literária oral e/ou escrita, pode-se ter uma ideia da complexidade e riqueza da literatura do país, ainda praticamente inexplorada, via tradução, por leitores estrangeiros.

A complexa situação linguística do Suriname precisa ser apresentada antes de que se possa tratar da literatura do país, posto que estão em íntima relação. A proibição de costumes e de manifestações culturais dos escravizados e a proibição que se fazia a esses do uso da língua holandesa faz surgir a inevitável questão: que línguas, ou línguas, eram faladas na antiga colônia e que línguas ainda são faladas no Suriname atual?

Os africanos provinham de diferentes regiões da África Ocidental e pertenciam a diferentes grupos étnicos e linguísticos, o que fez com que surgisse um pidgin na colônia, que logo se tornaria um crioulo, o Sranantongo (literalmente, Língua do Suriname). Esse se tornaria a principal língua do país, embora não tenha sido o único a se desenvolver a partir do crioulo original das plantações e não seja tampouco o único que continua em uso no Suriname atual (MIGGE 2003).

O Sranantongo, embora resultado da confluência de várias línguas africanas e, mais tarde, de línguas ameríndias, é um crioulo de base inglesa. Isso se explica pela política colonial "corporativa" da Companhia das Índias Ocidentais. Embora tenha conquistado o direito definitivo sobre a colônia, os holandeses permitiram a manutenção de posse de ingleses donos de plantações já estabelecidos no território. A língua, nessas plantações, era o inglês dos brancos e a língua de contato tanto entre brancos e escravos como entre os africanos de 
origens diferentes era um crioulo de base inglesa, justamente o Sranantongo, que se manteve mesmo depois da partida dos ingleses.

A população autóctone da colônia tinha, na medida do possível, uma boa relação com os antigos colonizadores ingleses e com os novos colonizadores holandeses, principalmente depois do acordo de paz firmado em 1684 que proibiu a escravização de aruaques, caribes e waraos. Além de manterem seus idiomas originais, os indígenas também se serviam do Sranantongo para comunicações interétnicas e contribuíram para a formação da língua, principalmente do ponto de vista do vocabulário.

O uso do Sranantongo nos tempos da colônia aponta para mais uma semelhança com o Brasil: no Suriname, como no Brasil pré-pombalino, a língua mais falada pela população, inclusive pelos brancos, era um crioulo. No caso do Suriname, o Sranantongo era, até pelas questões legais envolvendo a língua holandesa apontadas acima, o vernáculo da colônia. Esse fato teve consequência para formação literária do país e é também representado na literatura, sobretudo nos romances históricos.

A população branca do Suriname colonial era diminuta se comparada a outros grupos étnicos, e era formada principalmente pelos funcionários enviados pela metrópole e pelos donos das plantações. Desses, uma parcela considerável era formada por fazendeiros judeus. A história dos judeus nas Guianas é anterior à efetiva colonização holandesa, pois já à época dos britânicos houve iniciativas de estabelecer colônias judaicas no que hoje é a Guiana e em parte do território atual do Suriname, isso antes do Tratado de Breda de 1667.

Depois de 1654, os judeus sefarditas portugueses que viviam sob proteção dos holandeses no Nordeste do Brasil fugiram sobretudo para Amsterdã, de onde regressaram para a América via Caiena para depois levarem sua experiência no cultivo da cana de açúcar para a colônia do Suriname, onde se estabeleceram em grande número. Os portugueses se estabeleceram sobretudo às margens do Cassipora, em um local no interior, afastado de Paramaribo, em uma região que se tornaria conhecida como Jodensavanne (EMMERING 1975; BUDDINGH' 2012).

Os portugueses levaram para o Suriname mais do que sua experiência agrária. Levaram também suas tradições sefarditas e seus costumes lusobrasileiros, inclusive a língua portuguesa, que exerceu grande influência sobre o Saramakaans, uma das línguas utilizadas nas fazendas desde o século XVII e também língua dos quilombolas fugitivos das plantações dos ingleses, holandeses e portugueses (CHARRY et al. 2006). Essa língua continua sendo falada hoje e conta com uma literatura oral e escrita que ainda traz reflexos não só da língua, mas da tradição literária judaico-portuguesa. A presença do judeu luso-brasileiro no Suriname exerceu influência sobre a literatura produzida no Suriname tanto do ponto de vista da sua colaboração direta como comunidade produtora de material literário como do ponto de vista de sua representação na literatura nacional surinamesa.

Além das comunidades anteriormente apresentadas, naturalmente ainda há muitas etnias e grupos linguísticos do Suriname. Neste artigo destacarei outros dois grupos, em virtude do recorte adotado, a saber, a literatura surinamesa 
produzida em língua holandesa. São eles os descendentes das diásporas indiana e javanesa.

Os primeiros indianos chegaram ao Suriname em 1873, vindos do norte da Índia, das atuais regiões de Uttar Pradesh, Bihar e Bengala. Os indianos foram substituir a mão de obra escrava nas plantações depois da abolição da escravatura em 1863. Outros grupos já tinham migrado para o Suriname, como por exemplo migrantes da Ilha da Madeira, de outras regiões do Caribe e da China, mas a maioria dessas experiências não deu certo (BUDDINGH' 2012, HASSANKHAN et al. 2017).

Os indianos já eram empregados como trabalhadores temporários, com contratos de em média cinco anos, na então Guiana Inglesa. A experiência foi tão bem-sucedida que um acordo entre Inglaterra e Holanda foi firmado em 1870 para que o mesmo modelo fosse adotado no Suriname, sob a supervisão britânica. Entre 1873 e 1916, mais de trinta mil trabalhadores seguiram para o Suriname, tendo a maioria permanecido no país após o término de seu contrato de trabalho inicial.

A fixação no Suriname se deu por várias razões: pelo endividamento com os donos das plantações, o que impedia o retorno grátis à Índia estipulado em contrato, pela constituição de novas famílias no território e, em alguns casos, por terem eles mesmos se tornado pequenos proprietários de terras. No caso dos hindus, a dissolução do rígido sistema de castas no território do Suriname, fenômeno impossível ocorrer na realidade indiana da época, também dificultou a volta ao país de origem e a readaptação ao sistema milenar. Quanto aos muçulmanos, que constituíam parcela significativa dos trabalhadores, o novo país abria possibilidades que a Índia natal não podia oferecer tanto em termos religioso-culturais quanto econômicos.

Os indianos, não sem enfrentar muitas dificuldades, tornaram-se parte da já multiétnica sociedade surinamesa. Embora a maioria dos recém-chegados fossem camponeses iletrados, havia também entre os hindus pessoas originárias de castas superiores e com acesso à leitura e à escrita, fato também observado na população muçulmana. Ambos os grupos levaram ao país de adoção uma rica tradição literária que se mostraria de grande relevância para a literatura surinamesa. Os indianos estabeleciam suas próprias escolas e, como passar do tempo, começaram a frequentar as escolas coloniais de língua holandesa e mesmo a estimular seus filhos a fazê-lo.

A migração javanesa ocorreu entre 1890 e 1939 em circunstâncias muito semelhantes à migração dos indianos, com a diferença de que os javaneses provinham de território colonial holandês na atual Indonésia. Inicialmente camponeses, os javaneses passaram a ocupar outras funções laborais no Suriname, principalmente depois da Segunda Guerra Mundial, quando muitos passaram a se dedicar a atividades como o comércio ou à extração de bauxita.

Os javaneses mantiveram em grande parte sua língua e suas tradições, como o teatro de marionetes Wayang. Entretanto, a migração para centros urbanos fez com que a língua holandesa e o Sranantongo se tornassem cada vez mais importantes. Hoje, os escritores surinameses de ascendência javanesa tanto residentes no Suriname como na sua nova diáspora na Holanda escrevem em 
holandês, mas em vários deles, sobretudo os que se dedicam ao tema da diáspora, ainda há reverberações do javanês que para muitos é língua materna ou uma língua familiar.

Uma vez apresentado um panorama da formação do Suriname e de sua população sem o qual o leitor brasileiro interessado na produção literária do país vizinho provavelmente se sentiria perdido, é chegado o momento de tratar de modo mais específico da literatura surinamesa. Vista à luz da história do país, a literatura do Suriname não poderia deixar de refletir o acúmulo e a superposição de diferentes tradições literárias, dos mais diversos gêneros e dos mais diferentes temas manifestados de forma oral e escrita. Uma proposta de definição da literatura do Suriname, e que servirá como referência para a discussão, é a que segue:

A literatura surinamesa compreende todos os textos orais e escritos e demais expressões (interações) que possuem aspecto de literariedade produzidos em uma ou mais línguas em uso no Suriname e que fazem parte do processo retroativo-histórico de contribuição para uma das tradições que constituem a identidade nacional do Suriname. (VAN KEMPEN, 2003, p. 81, tradução nossa). ${ }^{1}$

A literatura surinamesa, a exemplo da brasileira, pode ser dividida em literatura sobre o Suriname, Literatura no Suriname e Literatura do Suriname. Na impossibilidade de apresentar aqui uma descrição detalhada da história da formação da literatura surinamesa e de suas diferentes fases, passo a destacar alguns aspectos que perpassam essas etapas e que fazem mais sentido no âmbito da presente discussão. Além do multilinguismo que se manifesta inclusive nas obras escritas em holandês, aparecem também o multiculturalismo, o entre-lugar, a crioulidade, a oralidade e a resistência (VAN KEMPEN 2002).

A literatura oral do Suriname, embora não seja objeto deste artigo, tem desempenhado papel importante no desenvolvimento da literatura escrita. Além da literatura oral dos povos autóctones, também os africanos escravizados e os demais grupos étnicos que formaram a nação surinamesa levaram para seu novo país suas tradições orais, sejam elas religiosas, literárias ou manifestações que não cabem nesse dualismo tão ocidental. Embora hoje não tão difundida como antes, a literatura oral em suas diversas manifestações e que perpassa praticamente todo o espectro étnico e linguístico encontra eco na literatura escrita produzida no Suriname ainda hoje.

A literatura surinamesa é produzida quase que totalmente em holandês, apesar da variedade linguística descrita acima. A tradição de escrever em sranantongo, principalmente poesia, persiste, e a literatura em sarnami ainda

\footnotetext{
${ }^{1}$ Texto original: Surinaamse literatuur omvat alle orale en geschreven teksten en andere communicatieve uitingen (interacties) die een aspect van literariteit bezitten, voortgebracht in een of meer van de door groepen gehanteerde talen van Suriname, en die deel uitmaken van het retroactief-historische proces van bijdragen aan een van de tradities die de nationale identiteit van Suriname constitueren.
} 
resiste, assim como a em javanês, mas cada vez mais surinameses adotam o holandês como sua língua de expressão literária. É um holandês com características próprias, uma variante conhecida como Surinaams-Nederlands, e seu uso como língua literária, sobretudo na literatura produzida em território nacional, atende a um projeto de afirmação da identidade surinamesa via literatura. $\mathrm{O}$ uso do holandês como língua literária perpassa as fronteiras étnicas, sendo meio de expressão de autores que se servem desse idioma para tratar de questões atinentes - ou não - à sua comunidade de origem e como ela se insere no projeto que construção da nação surinamesa.

O Suriname é uma terra de poetas e de leitores de poesia, o que é admirável se tomarmos em conta a situação da poesia na contemporaneidade. Além disso, uma característica bastante chamativa da literatura surinamesa é a presença feminina. As mulheres, especialmente na prosa, se destacam em número e em qualidade literária. Outra característica é o fato de a literatura surinamesa ser uma literatura em trânsito, produzida e consumida nos dois lados do Atlântico.

Muito antes da independência do Suriname em 1975, surinameses radicados na antiga metrópole já produziam literatura com temática e marcas estilísticas do país natal. Esses autores se deslocavam e ainda se deslocam com frequência entre os dois continentes e sua literatura reflete questões de pertença e de identidade. Naturalmente, há e sempre houve literatura surinamesa tanto na América como na Europa que se afastam da temática nacional e atende a outros propósitos temáticos e estéticos, mas em linhas gerais, a literatura surinamesa está realmente voltada para a produção de uma tradição literária embasada em questões nacionais.

Uma distinção que se pode arbitrar entre a literatura surinamesa produzida na Europa e a produzida na América é que o ramo europeu cada vez mais está a cargo dos descendentes dos imigrantes surinameses, que escrevem sobre sua própria identidade ao tocar em temas como sua relação com o país de seus pais e avós, a comunidade surinamesa na Holanda e sua integração na sociedade holandesa. Os autores radicados no Suriname, por outro lado, tratam de questões identitárias ao discutir as relações interétnicas e o papel de sua própria comunidade étnico-linguística no país. Além disso, o resgate de tradições e de fatos históricos constitui traço importante da sua produção literária.

Em termos de crítica, a literatura do Suriname ainda está restrita ao sistema literário de língua holandesa, e com muita frequência o critério utilizado é a sua aproximação ao que se faz mormente na literatura da Holanda, o que é muito perceptível em textos críticos como De geest van Waraku, do pesquisador holandês Michiel van Kempen, no qual o autor tende a dar mais ênfase às obras que se encaixam no marco da literatura ocidental, muito embora ele conceda espaço para a discussão da crioulização e do multilinguismo, sem o que não há que se falar em literatura surinamesa.

Uma leitura crítica da literaturs surinamesa deveria ter sempre em mente que o Suriname, como o restante do Caribe e como o Brasil, em maior ou menor escala, traz na sua literatura marcas de tradições literárias não-ocidentais escritas e principalmente orais, e que é aí que reside seu caráter inovador. Novas visadas 
críticas viriam, acredito, se a literatura do Suriname circulasse em tradução, o que permitiria uma reflexão mais plural sobre essa literatura.

Cabe agora fazer algumas considerações sobre a relação da literatura do Suriname com a tradução. A literatura surinamesa apresenta uma dinâmica muito particular no que toca às traduções. A literatura produzida em outros idiomas nacionais, mormente o sranantongo, é traduzida para o holandês, mas de maneira irregular, pois não se traduz tudo, nem de todas as épocas, nem de todos os gêneros, nem de todas as línguas. O que se observa, portanto, é uma dinâmica interna de traduções, sobretudo no sentido línguas nacionais - língua oficial.

O fenômeno de tradução interna, para consumo de diferentes comunidades étnico-linguísticas que compartilham o mesmo território nacional, não é desconhecido em países plurilíngues; basta tomar a Índia ou a Nigéria como exemplo. Porém, a semelhança termina aí, pois enquanto naqueles países a tradução para a língua oficial ou de grande circulação como o inglês ou o hindi permite a circulação da literatura originalmente produzida em outras línguas nacionais, literaturas essas que continuam a ser produzidas de modo regular, esse não é o caso no Suriname, como descrevi acima.

Outra diferença é o fato de a migração dessa literatura se dar no sentido línguas minoritárias - língua hegemônica (no caso do inglês). Isso tem dois efeitos: o primeiro é, como mencionei acima, a circulação da literatura em território nacional atravessando barreiras linguísticas. Outro, e aí reside a diferença no caso do Suriname, é a possibilidade de circulação e de tradução para além das fronteiras nacionais. O holandês, embora conte com mais de 24 milhões de falantes espalhados pela Europa e América, não é exatamente uma língua de grande circulação, ao contrário do inglês.

O aspecto particular da dinâmica de tradução no Suriname pode ser atribuído, assim, pela ausência de um segundo movimento, ou seja, a tradução para outras línguas que não o holandês. A tradução para além das fronteiras nacionais é quase inexistente e a literatura surinamesa produzida originalmente em holandês ou traduzida para esse idioma tem sua circulação restrita aos países de língua holandesa, sobretudo à Holanda.

Não é tarefa simples oferecer tentativas de explicação para a ausência da literatura surinamesa em tradução, em termos globais. À primeira vista, a literatura do país apresenta características atraentes do ponto de vista da temática, pois aborda questões como identidade, desterritorialização, afirmação nacional. Não é diferente, portanto, da literatura produzida em outras regiões do Caribe, região à qual o Suriname se filia em termos culturais (ARNOLD 2001; KEMPEN 2003). Da perspectiva das várias vertentes do Pós-colonialismo, mas não só, é uma literatura que mereceria um olhar mais atento do resto do mundo.

Uma primeira tentativa de explicar essa ausência seria pela língua na qual a literatura do Suriname é produzida. Entretanto, o fato é que embora o holandês não seja uma língua de grande difusão, a literatura europeia produzida nesse idioma encontra ampla acolhida via tradução, como uma simples consulta ao Index Translationum da Unesco pode atestar. Não é, portanto, uma impenetrabilidade da língua holandesa ou a ausência de tradutores do holandês para as mais diversas línguas que impede a tradução de obras do Suriname. 
Outras questões se oferecem como explicações mais palpáveis. A condição periférica do Suriname dificulta a sua inserção no panorama literário internacional. Essa condição periférica se manifesta dentro do sistema literário de língua holandesa, no qual o Suriname ocupa um lugar secundário tanto do ponto de vista da sua distribuição e consumo quanto da sua presença nos compêndios de historiografia e de crítica de literatura em língua holandesa (VAN KEMPEN 1993, 2003).

Além disso, ao contrário da Bélgica e da Holanda, o Suriname não conta com um órgão de fomento à tradução, iniciativa custosa demais para um país de poucos recursos. O relativo desconhecimento da existência do Suriname em termos globais contribui para que seja ignorada a sua literatura, e o rompimento desse desconhecimento do país e de sua literatura passa necessariamente pela tradução.

No que toca à tradução da literatura surinamesa no Brasil, a situação é, até o momento, semelhante à do resto do mundo, ou seja, de ausência, embora já exista tradução de textos surinameses em diferentes etapas de produção no país, notadamente no âmbito do Núcleo de Estudos Germânicos da Universidade de Brasília. Os motivos pelos quais a literatura surinamesa merece tradução no Brasil estão esboçados no que se disse até aqui, mas convém enfatizar, mais uma vez, as semelhanças existentes entre os dois países para reforçar a existência desse nascente projeto de tradução.

A literatura surinamesa merece uma apresentação que transmita todo seu potencial ao leitor brasileiro, mas o que deve aparecer na apresentação da literatura surinamesa ao público brasileiro, evitando-se sempre o apelo fácil do "exotismo" e da "cor local", é uma questão em aberto. Temas como etnia e identidade, questões estéticas e de estilo, agenda política são algumas das trilhas que se abrem diante do tradutor da literatura do nosso vizinho.

Aponto para a possibilidade de que se possa estabelecer um diálogo entre os sistemas literários brasileiro e surinamês por meio da tradução para o português brasileiro de literatura do Suriname, em especial dos romances históricos, e particularmente aqueles que têm a diáspora como tema. O Brasil e o Suriname compartilham uma história de migrações forçadas e relatos sobre essas migrações perpassa o sistema literário de ambos os países. Vale relembrar que a comunidade judaica do Suriname tem suas origens em grande parte no Brasil e que o comércio de escravos seguia uma rota similar entre a África, o Brasil e o Suriname. Dado que o tema da diáspora judaica e da escravidão africana são temas recorrentes na literatura surinamesa, presume-se que o leitor brasileiro possa se interessar pela representação desses temas que lhe são tão familiares e que se disponha a ler literatura surinamesa traduzida para o português brasileiro. De qualquer modo, a recepção da literatura surinamesa traduzida é a um só tempo um desafio e uma incógnita que se desvelará à medida que os textos forem aparecendo no mercado editorial brasileiro. 


\section{REFERÊNCIAS}

ARNOLD, A. James. A History of Literature in the Caribbean. Vol. 2: English and Dutch-Speaking Regions. Amsterdam: John Benjamins, 2001.

BUDDINGH', Hans. Geschiedenis van Suriname. Amsterdam: Nieuw Amsterdam Uitgeverij, 2012.

CHARRY, Eddy; KOEFOED, Geert; MUYSKEN, Pieter (ed.). De talen van Suriname. Amsterdam: Coutinho, 2006.

EMMERING, S. De kolonisatie van de Portugeesch Joodsche natie in Suriname en de geschiedenis van de Joden Savanne. Amsterdam: S. Emmering, 1975.

HASSANKHAN, Maurits; ROOPNARINE, Lomarsh; MAHASE, Radica (ed.). Social and Cultural Dimensions of Indian Indentured Labour and its Diaspora. London: Routledge, 2017.

JABINI, Franklin Steven. Christianity in Suriname: An Overview of its History, Theologians and Sources. Carlisle: Langham, 2012.

MIGGE, Bettina. Creole Formation as Language Contact: The case of the Suriname Creoles. Amsterdam: John Benjamins, 2003.

VAN KEMPEN, MICHIEL. De geest van Waraku. Kritieken over Surinaamse literatuur. Haarlem/Brussel, 1993.

VAN KEMPEN, MICHIEL. Een geschiedenis van de Surinaamse literatuur (2 volumes). Breda: De Geus, 2003.

Julio Cesar Neves Monteiro

CesarJ1@,gmail.com

Recebido em: 30/9/2017

Aceito em: 28/2/2018

Publicado em Abril de 2018 